\title{
Impact of Sterilization Exposure Time on Leaf Explants of Anthurium cv. Xavia for Establishing an Aseptic Culture
}

\author{
Rashmita Toppo $^{1^{*}}$ and Sashikala Beura ${ }^{2}$ \\ ${ }^{1}$ Floriculture and Landscaping, College of Agriculture, OUAT, India \\ ${ }^{2}$ Floriculture and Landscaping, College of Agriculture and BTCC, OUAT, India \\ *Corresponding author
}

\section{A B S T R A C T}

Keywords

Anthurium,

Sterilization,

Survival, $\mathrm{HgCl}_{2}$

Article Info

Accepted:

20 August 2018

Available Online:

10 September 2018
Conventional propagation of Anthurium (Anthurium andraeanum [Lind.]) plant through seeds and suckers is a tedious and very slow process and not practical when carried out commercially on large scale. Hence, biotechnological approach such as micropropagation is considered as a novel method for production of pathogen-free true-to-type plantlets at a faster rate. In the present study, a proficient surface sterilization procedure was standardized for aseptic culture from leaf explants of Anthurium $c v$. Xavia, under in-vitro conditions. The leaf explants were exposed to $0.1 \% \mathrm{HgCl}_{2}$ for $2,3,4,5,6,7$ and 8 min) and control (distilled water) were cultured on MS media. The leaf explants exposed for 5 minutes resulted in minimum fungal $(0.00 \%)$ and bacterial $(0.18 \%)$ contamination with maximum survival percentage $(97.66 \%)$ at 60 days after inoculation. The most effective surface sterilization time was taken into consideration for further sterilization explants and in-vitro culture in the MS basal media supplemented with of bio-regulators along with control for production of pathogen-free callus development of anthurium.

\section{Introduction}

Anthurium is one of the most demanded tropical ornamental cut flowers due to its attractive bright coloured spathe, glossiness and longer shelf life. Anthurium is also sold as a potted plant because of its shade-loving nature, air purifying ability, attractive foliage and slow growth. The traded value of Anthurium exceeds its position ahead of Cymbidium among tropical orchids among the tropical flowers (CBIMI, 2016). They are very popular as cut flowers for their beauty and long lasting qualities which are essential prerequisites for any floral arrangement. There are many cultivars with coloured spathes starting from red, orange, pink, coral, purple, white and bi-colours like red-green, orangegreen, pink-green and white-green are known as obake and they are extremely variable in size and shape.

Commercial cultivation of anthurium has been taken up in Kerala, Karnataka, Tamil Nadu, West Bengal, Sikkim, Maharastra and pockets of North Eastern parts of India under semishade condition. In Odisha also cut anthurium flowers are widely used in bouquets and flower arrangements and mainly they are procured from the neighbouring states as its 
commercial cultivation has not yet been started. Many Anthurium cultivars can be grown commercially under protected structures in Odisha, but planting materials are quite costlier as well as transportation cost is high as procured from outside states. Hence, there is an urgent need for production of disease-free healthy planting materials of suitable varieties recommended for commercial cultivation in Odisha under the shade-net structure.

Conventional propagation through seeds is not a commercial method as seed setting and maturity is a very lengthy process, also the production of desired true coloured spathes is a problem due to low seedling vigour, poor vegetative growth and some amount of variability due to inherent heterozygosis. Therefore, traditional techniques of vegetative propagation through stem cuttings and suckers exist, despite homogenous materials, it is a tedious and very slow process and not practical when carried out commercially in a large scale. Presently, biotechnological approach such as micro propagation is found to be a novel method for production of pathogen-free true-to-type plantlets in a faster rate.

Therefore, keeping in view of the above background, the present investigation was carried out for production of true-to-type plantlets through in-vitro cloning. The most crucial and challenging step in micro propagation is sterilization of explants for aseptic culture establishment without pathogen contamination. Contamination of explants depends upon different factors like plant species, age, type and source of explants, growing condition and prevailing macro and micro environment. According to the study of Leifert et al., (1989, 1994) losses due to contamination under in-vitro conditions vary between $3-15 \%$ on an average in commercial and scientific plant tissue culture laboratories which are mainly caused by fungus, yeast and bacteria. Taking all these into consideration, therefore, the present study was conducted to establish a proficient protocol for standardization of leaf explants sterilization of Anthurium andraeanum (Lind.) $c v$. Xavia, to obtain contamination free culture.

\section{Materials and Methods}

\section{Sterilization of glassware and tools}

The glassware and culture tubes used for the experiment were dipped in the diluted $(10 \mathrm{x})$ chromic acid solution overnight. These were then washed thoroughly with a detergent solution followed by washing under running tap water and again rinsed several times with distilled water followed heat sterilization in a hot air oven for 2 hours at $150^{\circ} \mathrm{C}$. Forceps, Petri dish and scalpel were thoroughly wiped with isopropanol, wrapped with paper and steam sterilized in the autoclave for 20 minutes at $15 \mathrm{psi}$ and $121^{\circ} \mathrm{C}$. The working chamber of laminar airflow cabinet was wiped with isopropanol and filtered air (80-100 cubic $\mathrm{ft} / \mathrm{min}$ ) was blown for 5 minutes then the sterilized tools were exposed to UV light for 30 minutes in the chamber.

\section{Media preparation for in-vitro culture}

In the present study analytical reagents of excel R grade of Titan Biotech Ltd., Ranbaxy Laboratory Ltd., Merck (India), Qualigen Fine Chemicals, and Himedia Laboratories Ltd. (India) were used. MS Medium (Murashige and Skoog, 1962), Auxins, Cytokinins, Myoinositol and Fe-EDTA used for media preparation were supplied by Sigma (USA) and Agar from Ranbaxy Laboratory Ltd. Required quantities of macronutrients, micronutrients, vitamins and plant bioregulators were taken from the stock solution and required quantity of sucrose dissolved in distilled water was added fresh to 
the medium. The $\mathrm{pH}$ of the solution was adjusted to $5.6 \pm 0.1$ using $0.1 \mathrm{~N} \mathrm{NaOH}$ or $0.1 \mathrm{~N}$ $\mathrm{HCl}$ and volume was made up to $1 \mathrm{~L}$ with distilled water. After adding Agar (0.6\% w/v) as a gelling agent to the medium, it was then boiled and poured into the culture tube followed by plugging. Culture tube containing culture medium was steam sterilized in the autoclave at $121^{\circ} \mathrm{C}$ and 15 psi pressure for the 20 minutes. The sterilized medium was then kept in the laminar airflow chamber for cooling.

\section{Source of explants}

The investigation was carried out in the laboratories of Biotechnology-cumCommercial Tissue Culture Centre, OUAT, Bhubaneswar. Healthy and disease free $3^{\text {rd }}$ and $4^{\text {th }}$ light green coloured leaves of Anthurium andraeanum $c v$. Xavia were collected from the mother plants maintained under shade nethouse using a clean blade.

\section{Surface sterilization of explants}

Freshly collected leaves were washed under running tap water. The following steps were undertaken for surface sterilisation,

\section{Phase-I}

Leaf explants obtained from the mother plants were cut into segments for easy handling and subjected $1 \%$ Tween 20 solution for 15 minutes. Then the explants were treated with $2 \%$ solution of Carbendazim 50\% WP for 20 minutes and rinsed 3-4 times with distilled water. These explants were then taken to the laminar air flow chamber for further sterilization.

\section{Phase-II}

Inside the laminar flow the leaf explants were treated with $0.1 \% \quad \mathrm{HgCl}_{2}$ with time of exposure for $\mathrm{T}_{2}-2 \mathrm{~min}, \mathrm{~T}_{3}-3 \mathrm{~min}, \mathrm{~T}_{4}-4$ $\min , \mathrm{T}_{5}-5 \mathrm{~min}, \mathrm{~T}_{6}-6 \mathrm{~min}, \mathrm{~T}_{7}-7 \mathrm{~min}$ and $\mathrm{T}_{8}$ $-8 \mathrm{~min}$; followed by rinsing 5-6 times with sterile water. Explants were again treated with $0.1 \% \mathrm{KCl}$ solution for $1 \mathrm{~min}$ for dissolving the residual mercury if any, as it is toxic to both plant and animal and again rinsed 4-5 times with sterile water. For control $\left(\mathrm{T}_{1}\right)$ explants were only washed with distilled water 5-6 times.

\section{Inoculation}

The cut ends that have turned brown due to exposure to sterilizing agent of the sterilized leaf explants were removed and cut rectangular pieces of $1 \mathrm{~cm}^{2}$ size and then inoculated on MS medium supplemented with growth hormones BAP (2.0 mg/l) and 2, 4-D $(0.5 \mathrm{mg} / \mathrm{l})$ with $6 \%(\mathrm{w} / \mathrm{v})$ agar, $30 \%(\mathrm{w} / \mathrm{v})$ sucrose. Observation for the parameters i.e., fungal, bacterial, death, aseptic and survival percentage of explants was recorded at 15, 30, 45 and 60 Days after inoculation (DAI). The treatment having the maximum survival percentage with minimum infection and death percentage was taken as the standard time for sterilizing explants for further in vitro culture.

\section{Establishment of culture}

After inoculation, the culture tubes were kept at $25 \pm 2{ }^{\circ} \mathrm{C}$ in aseptic an air conditioned room with 2 months dark period and $75 \%$ relative humidity.

\section{Statistical analysis}

The experiment was conducted in a completely randomized design with three replications. The raw data obtained during the experimental observations were transformed wherever required and then subjected to single factor analysis of variance (ANOVA) as per method by Gomez and Gomez, (1984). The significance of the treatment effects was 
judged with the help of ' $F$ ' variance ratio test. Calculated ' $F$ ' value was compared with the table value of ' $F$ ' at $5 \%$ level of significance.

\section{Results and Discussion}

The response of sterilization time exposure of leaf explants of anthurium $c v$. Xavia to $0.1 \%$ $\mathrm{HgCl}_{2}$ in relation to contamination is depicted in Table 1, 2 and 3. Observing the inoculated explants for 2 months, it was revealed that increasing time of exposure to $\mathrm{HgCl}_{2}$ significantly reduced contamination but exhibited adverse effect on explants. Observation taken at 15 DAI showed that among the different treatments, maximum fungal $(30.74 \%)$ and bacterial $(27.89 \%)$ contamination percentage was recorded with control ( $\mathrm{T}_{1}$-distilled water).

Minimum fungal contamination $(0.00 \%)$ was recorded with 5 min exposure to $\mathrm{HgCl}_{2}$ followed by $6 \mathrm{~min}$ treatment with $0.39 \%$ fungal contamination (Table 1), whereas, minimum bacterial contamination $(0.00 \%)$ was recorded with $5 \mathrm{~min}, 6 \mathrm{~min}, 7 \mathrm{~min}$ and 8 min exposure at15 DAI. Because of the adverse effect of $\mathrm{HgCl}_{2}$ death of explants occurred due to the browning of leaf tissues, and the maximum dead tissues $(5.32 \%)$ were observed with 8 min exposure while minimum death $(1.38 \%)$ was observed with 5 min exposure time at 15 DAI. As there was minimum contamination observed with $5 \mathrm{~min}$ exposure time, maximum percentage of aseptic culture $(100.00 \%)$ was recorded at 5 min followed by $6 \mathrm{~min}(99.61 \%)$ and the minimum were obtained in $\mathrm{T}_{1}(41.37 \%)$.

Observation recorded at 30 DAI (Table 2) explained that the explants treated for $5 \mathrm{~min}$ and $6 \mathrm{~min}$ resulted with minimum fungal $(0.00 \%)$, bacterial $(0.00 \%)$ contamination with $100.00 \%$ aseptic culture. Results depicted at 45 DAI and 60 DAI (Table 3 and 4) also showed the similar trend with $0.00 \%$ fungal and bacterial contamination in both the cases treated for $5 \mathrm{~min}$. However, explants treated for 6 min with $\mathrm{HgCl}_{2}$ also showed minimum bacterial contamination $(0.00 \%)$. The explants that did not survive the whole process were seen maximum i.e. $5.93 \%$ and $5.93 \%$, with 8 min time exposure to $\mathrm{HgCl}_{2}$ at $45 \mathrm{DAI}$ and 60 DAI respectively.

Table.1 Effect of surface sterilization time on the level of contamination and aseptic culture from leaf explants of anthurium $c v$. Xavia at 15 DAI

\begin{tabular}{|c|c|c|c|c|}
\hline Treatments & Fungal \% & Bacteria \% & Death \% & Aseptic \% \\
\hline $\mathrm{T}_{1 \text { (Distilled water) }}$ & $30.74(35.21)$ & $27.89(31.85)$ & $2.71(9.46)$ & $41.37(40.07)$ \\
\hline$T_{2(2 \min )}$ & $24.28(29.52)$ & $16.89(24.26)$ & $2.43(9.55)$ & $58.83(49.70)$ \\
\hline $\mathbf{T}_{3(3 \mathrm{~min})}$ & $18.46(25.47)$ & $12.36(20.57)$ & $1.99(8.04)$ & $69.19(60.53)$ \\
\hline $\mathbf{T}_{4(4 \mathrm{~min})}$ & $5.15(13.11)$ & $6.18(14.39)$ & $1.60(7.27)$ & $88.67(70.36)$ \\
\hline $\mathbf{T}_{\mathbf{5}(5 \mathrm{~min})}$ & $0.00(0.00)$ & $0.00(0.00)$ & $1.38(6.72)$ & $100.00(90.00)$ \\
\hline $\mathrm{T}_{6(6 \mathrm{~min})}$ & $0.39(2.00)$ & $0.00(0.00)$ & $2.63(9.33)$ & $99.61(87.92)$ \\
\hline$T_{7(7 \mathrm{~min})}$ & $0.88(5.68)$ & $0.00(0.00)$ & $4.35(12.02)$ & $99.12(84.71)$ \\
\hline $\mathrm{T}_{8(8 \mathrm{~min})}$ & $1.40(6.79)$ & $0.00(0.00)$ & $5.32(13.34)$ & $98.60(83.33)$ \\
\hline $\operatorname{SEm}( \pm)$ & 0.93 & 0.15 & 0.43 & 1.68 \\
\hline CD 5\% & 2.78 & 0.44 & 1.30 & 5.03 \\
\hline
\end{tabular}

(Values in the parenthesis are Arc sign transformed values) 
Table.2 Effect of surface sterilization time on the level of contamination and aseptic culture from leaf explants of anthurium $c v$. Xavia at $30 \mathrm{DAI}$

\begin{tabular}{|c|c|c|c|c|}
\hline Treatments & Fungal \% & Bacteria \% & Death \% & Aseptic \% \\
\hline $\mathrm{T}_{1 \text { (Distilled water) }}$ & $49.6144 .77)$ & $31.80(34.32)$ & $3.26(10.40)$ & $18.59(25.54)$ \\
\hline $\mathrm{T}_{2(2 \mathrm{~min})}$ & $35.57(36.60)$ & $28.78(32.44)$ & $2.76(9.55)$ & $35.65(36.66)$ \\
\hline $\mathrm{T}_{3(3 \mathrm{~min})}$ & $20.61(27.00)$ & $17.77(24.91)$ & $2.88(9.79)$ & $61.63(51.53)$ \\
\hline $\mathrm{T}_{4(4 \mathrm{~min})}$ & $3.09(12.85)$ & $7.96(16.38)$ & $2.47(9.00)$ & $88.96(82.80)$ \\
\hline $\mathrm{T}_{5(5 \mathrm{~min})}$ & $0.00(0.00)$ & $0.00(0.00)$ & $2.18(8.48)$ & $100.00(90.00)$ \\
\hline $\mathrm{T}_{6(6 \mathrm{~min})}$ & $0.00(0.00)$ & $0.00(0.00)$ & $3.60(10.93)$ & $100.00(90.00)$ \\
\hline $\mathrm{T}_{7(7 \mathrm{~min})}$ & $0.87(3.09)$ & $2.09(6.79)$ & $4.89(12.77)$ & $97.04(80.11)$ \\
\hline $\mathrm{T}_{8(8 \mathrm{~min})}$ & $0.75(3.22)$ & $3.24(10.33)$ & $5.86(14.00)$ & $96.00(78.20)$ \\
\hline $\mathrm{SE}_{\mathrm{m}( \pm)}$ & 1.76 & 1.25 & 0.29 & 2.16 \\
\hline $\mathrm{CD} 5 \%$ & 5.28 & 3.75 & 0.86 & 6.46 \\
\hline
\end{tabular}

(Values in the parenthesis are Arc sign transformed values)

Table.3 Effect of surface sterilization time on the level of contamination and aseptic culture from leaf explants of anthurium $c v$. Xavia at 45 DAI

\begin{tabular}{|c|c|c|c|c|}
\hline Treatments & Fungal \% & Bacteria \% & Death \% & Aseptic \% \\
\hline $\mathrm{T}_{1 \text { (Distilled water) }}$ & $49.37(44.66)$ & $38.34(38.26)$ & $3.76(11.18)$ & $12.29(20.50)$ \\
\hline $\mathrm{T}_{2(2 \mathrm{~min})}$ & $38.55(38.38)$ & $32.78(34.92)$ & $3.20(10.30)$ & $28.66(32.37)$ \\
\hline $\mathrm{T}_{3(3 \mathrm{~min})}$ & $23.24(28.81)$ & $21.68(27.77)$ & $2.94(9.86)$ & $55.08(47.91)$ \\
\hline $\mathrm{T}_{4(4 \mathrm{~min})}$ & $7.31(18.09)$ & $8.59(17.04)$ & $2.79(9.61)$ & $84.10(66.54)$ \\
\hline $\mathrm{T}_{5(5 \mathrm{~min})}$ & $0.00(0.00)$ & $0.00(0.00)$ & $2.63(9.34)$ & $100.00(90.00)$ \\
\hline $\mathrm{T}_{6(6 \mathrm{~min})}$ & $0.90(4.99)$ & $0.00(0.00)$ & $4.45(12.18)$ & $99.10(86.85)$ \\
\hline $\mathrm{T}_{7(7 \mathrm{~min})}$ & $0.96(3.26)$ & $3.00(9.96)$ & $4.88(12.76)$ & $96.04(78.61)$ \\
\hline $\mathrm{T}_{8(8 \mathrm{~min})}$ & $1.77(7.52)$ & $2.87(9.730$ & $5.93(14.10)$ & $95.36(77.57)$ \\
\hline $\mathrm{SEm}_{\mathbf{m}( \pm)}$ & 2.42 & 0.23 & 0.14 & 1.25 \\
\hline $\mathrm{CD}_{5} \mathbf{5}$ & 7.26 & 0.69 & 0.41 & 3.75 \\
\hline
\end{tabular}

(Values in the parenthesis are Arc sign transformed values)

Table.4 Effect of surface sterilization time on the level of contamination and aseptic culture from leaf explants of anthurium $c v$. Xavia at $60 \mathrm{DAI}$

\begin{tabular}{|c|c|c|c|c|}
\hline Treatments & Fungal \% & Bacteria \% & Death \% & Aseptic \% \\
\hline$T_{1}$ (Distilled water) & $49.37(44.66)$ & $38.34(38.26)$ & $3.76(11.18)$ & $12.29(20.50)$ \\
\hline $\mathbf{T}_{2(2 \mathrm{~min})}$ & $38.55(38.38)$ & $32.78(34.92)$ & $3.20(10.30)$ & $28.66(32.37)$ \\
\hline$T_{3(3 \min )}$ & $23.24(28.81)$ & $21.68(27.77)$ & $2.94(9.86)$ & $55.08(47.91)$ \\
\hline$T_{4(4 \min )}$ & 7.31 (18.09) & 8.59 (17.04) & $2.79(9.61)$ & $84.10(66.54)$ \\
\hline$T_{5(5 \min )}$ & $0.00(0.00)$ & $0.00(0.00)$ & $2.63(9.34)$ & $100.00(90.00)$ \\
\hline$T_{6(6 \mathrm{~min})}$ & $0.90(4.99)$ & $0.00(0.00)$ & $4.45(12.18)$ & $99.10(86.85)$ \\
\hline$T_{7(7 \mathrm{~min})}$ & $0.96(3.26)$ & $3.00(9.96)$ & $4.88(12.76)$ & $96.04(78.61)$ \\
\hline$T_{8(8 \min )}$ & $1.77(7.52)$ & $2.87(9.730$ & $5.93(14.10)$ & $95.36(77.57)$ \\
\hline $\operatorname{SEm}( \pm)$ & 2.42 & 0.23 & 0.14 & 1.25 \\
\hline CD 5\% & 7.26 & 0.69 & 0.41 & 3.75 \\
\hline
\end{tabular}

(Values in the parenthesis are Arc sign transformed values) 
Fig.1 Survival percentage of leaf explant at 15, 30, 45 and 60 days after inoculation (O- observed value, T- angular transformed value, Cont.-control)

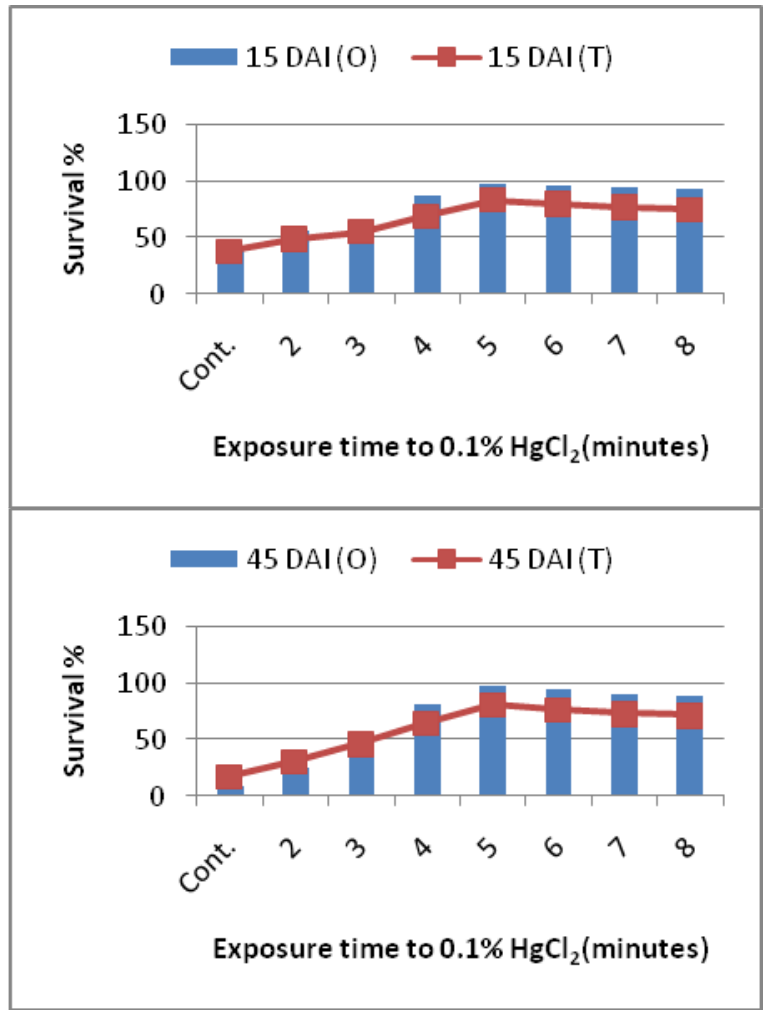

The mean percentage of clean surviving explants showed that the effectiveness of the sterilization procedure was maximum, with 5 min as compared to other treatments throughout the experiment (Fig. 1). Maximum survival percentage was recorded with $98.62 \%, 97.82 \%, 97.37 \%$ and $97.41 \%$ at 15 DAI, 30 DAI, 45 DAI and 60 DAI respectively confirming that leaf explants, when exposed to $\mathrm{HgCl}_{2}$ for 5 min is highly suitable for obtaining aseptic culture with minimal death of tissues and microbial contamination. Further increase in exposure time to $\mathrm{HgCl}_{2}$ led to a significant decline in the percentage survival of explants.

The surface sterilization procedures for explants typically depend on the type of explants and plant species (Rezadost et al., 2013). Exposure time to the sterilizing agent usually vary according to different plant parts depending on the softness and hardness of the

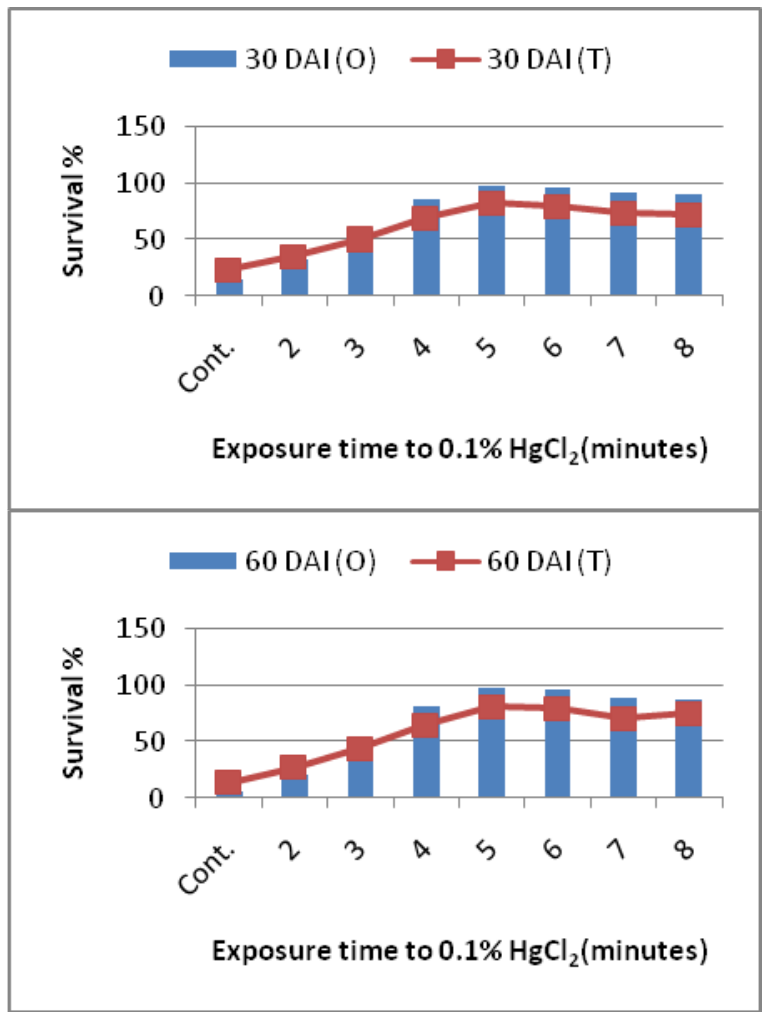

tissue (Sharma et al., 2014). Mercury chloride $(\mathrm{HgCl} 2)$ in a very low concentration $(0.1$ to $1.0 \%$ ) has been found an effective surface sterilizing agent in many plant species (Mamun et al., 2004).

In case of leaf explants, $96.39 \%$ clean and pathogen free culture were obtained with $0.1 \%(\mathrm{w} / \mathrm{v}) \mathrm{HgCl}_{2}$ at 5 minutes showing significant traces of both bacterial as well as fungal contamination at 60 DAI. Increase in the exposure of timing to $\mathrm{HgCl}_{2}$ led to the death of explants due to the heavy metal contamination of mercury which is toxic to both plants and animal in higher concentration or for a longer period proving phytotoxic that is against the survival of explants, in either way. $\mathrm{HgCl}_{2}$ having mainly anti-bacterial property was more efficient and showed more decontamination percentage with increase in the time of exposure (Gochhayat et al., 2017). 
Hence it is concluded from the present investigation, that $0.1 \% \mathrm{HgCl}_{2}$ can assure the explants sterility and regeneration capacity which were significantly influenced by the exposure times. The leaf explants of Anthurium $c v$. Xavia, exposed for 5 minutes to $0.1 \% \mathrm{HgCl}_{2}$ resulted in minimum fungal $(0.00 \%)$ and bacterial $(0.43 \%)$ contamination with maximum survival percentage $(97.41$ $\%)$.These findings will assist a good foundation for proficient and effortless surface sterilization of Anthurium leaf explants particularly when collected from field condition; as well as pathogen-free callus can be produced which could further be used for producing healthy plantlets under invitro condition.

\section{References}

CBI Market Intelligence, 2016. Trade Statistics Cut Flowers and Foliage, 2.

Gochhayat, A. A., Beura, S., and Subudhi, E., (2017). Effect of Surface Sterilization Time and Plant Bioregulators for Callus Formation in Hybrid Lilium Cv. Tresor. Biosciences biotechnology research Asia, 14(2): 709-713.

Gomez, K. A., and Gomez, A. A., (1984). Statistical procedures for agricultural research 3rd edn, John Wiley and Sons, Singapore, 680 .
Leifert, C., Morris, E. C., and Waites, W. M., (1994). Ecology of microbial saprophytes and pathogens in field grown and tissue cultured plants. Cri. Reviews Plant Sci. 13:139-183.

Leifert, C., Waites, W. M., and Nicholas, J. R., (1989). Bacterial contaminants of micropropagated plant cultures. J. App. Bacteriol. 67:353-361.

Mamun, M. A., Sikdar, M. B. H., Paul, D. K., Rahman, M. M., and Islam, M. R., (2004). In vitro micropropagation of some important sugarcane varieties of Bangladesh. Asian J. Plant Sci., 3: 666669.

Murashige, T., and Skoog, F., (1962). A revised medium for rapid growth and bioassays with tobacco cultures. Physiologia Plantarum, 15(3): 473-497.

Rezadost, H. M., Sohan, M. M., and Hatamzadeh, A. M. R. M., (2013). In vitro regeneration of sour orange (Citrus aurantium L.) via direct organogenesis: Plant Knowledge Journal; 2: 150-156.

Sharma, V., Srivasta N., Kamal B., Dobriyal, A.K., and Jadon S.V., (2014). Efficient sterilization protocols for different explants of an endangered: Trends in life sciences, www.sciencejournal.in, 3: 2319-5037.

\section{How to cite this article:}

Rashmita Toppo and Sashikala Beura. 2018. Impact of Sterilization Exposure Time on Leaf Explants of Anthurium $c v$. Xavia for Establishing an Aseptic Culture. Int.J.Curr.Microbiol.App.Sci. 7(09): 2850-2856. doi: https://doi.org/10.20546/ijcmas.2018.709.354 